\title{
Peculiarities of microevolution processes in Trollius asiaticus in South Siberia Mountains
}

\author{
Lyubov V. Buglova ${ }^{1 *}$ and Olga S. Zhirova ${ }^{1}$ \\ ${ }^{1}$ FSIS «Central Siberian Botanical Garden SB RAS», Novosibirsk, 630090, Russia
}

\begin{abstract}
In the paper, we analyse the distribution of species and forms closely-related to Trollius asiaticus L. growing in the mountains of South Siberia between the Altai Mountain Country and Baikalia. The interrelationship between the endemic species and forms of highmountains and parental lowland forms are adjacent-sympatric. We suppose the ways of disruptive selection to be of the same type, thus resulting in $T$. sajanensis and $T$. altaicus speciation, which are twin-species to each other. Between the parental and daughter species, there are interlayers of morphological forms being introgressive to both species. Key words: characters, populations, disruptive selection, introgression, speciation.
\end{abstract}

The morphometry of Trollius L. representatives was performed in the mountains of South Siberia, including the Altai Mountain Country, the Kuznetskiy Alatau mountain range, the Eastern and Western Sayan, the Tannu-Ola mountains. The mentioned mountains stretch for about $1500 \mathrm{~km}$ from the west to the East. The most wide-spread within this territory species $T$. asiaticus L. is characterised by high morphological plasticity. In the lower and middle parts of the forest belt, there grow several forms of this species, differing by petal width and beak length [1]. The common character is the petal length equal or almost equal to the sepal length. The upper parts of the forest and subalpine and the lower part of the alpine belts exhibit wider species diversity and the study on the distribution patterns allowed to follow the course of phylogenesis.

By analysing both herbaria of Komarov Botanic Institute RAS, NReaserch Tomsk State University, Central Siberian Botanical Garden SB RAS (LE; NS; NSK; TK) and samples collected in our expeditions we subdivided in the South Siberia mountains 4 regions by spreading there Trollius forms and species related to T. asiaticus (Fig. 1):

a) Regions with morphologically distinguishable separate species formation $-T$. altaicus C.A. Meyer is spread over most part of the Altai Mountain Country (Fig. 1, 1); the Tunka Range is the location of $T$. sayanensis (Malysh.) Sipl., while close to it forms grow in the mountains surrounding Baikal (Fig. 1, 4). We also include to this list some herbarium samples being identified as other species, usually, as T. kytmanovii Reverd., however they significantly deviate towards $T$. sajanensis. In Fig. 1 their area is marked by dotted line. Towards the parental species, there are sequences of intermediate forms of introgressive origin.

*Corresponding author: astro11@rambler.ru 
b) Regions with point prevalence of forms with debatable taxonomy rank (Fig. 1, 3), as they significantly differ from $T$. asiaticus, therefore do not present clear morphological or geographical differentiation.

c) Areas of $T$. asiaticus s. 1 (including morphologically close species of T. kytmanovii Reverd.) growth within all the altitudinal gradient.

Actually, T. asiaticus plants area is limited by the forest belt of low-mountains and midlands. However, some representatives occur in the high-mountains up to $2500 \mathrm{~m}$ above sea level, but only in the region 2 (Fig. 1, 2). In Baikalia, T. kytmanovii is described as spread in low-mountain forest belt, although, modern understanding of this species characters [2] hardly distinguishes it from $T$. asiaticus, while growth of both taxa representatives under similar conditions of the forest belt makes their subdivision into separate species quite controversial.

Alpine species T. sajanensis (Malysh.) Sipl. and T. altaicus C.A. Meyer are morphologically close by similar parameters on the petal length and the ratio of petals to sepals. The two species are very much alike by their habitus and flower size, and both are endemics: T. sajanensis grows at the Tunka Range, while T. altaicus - in high-mountain belt of the Altai Mountain Country. Nevertheless, considerable geographical cleavages of these species makes it possible to assume the same type of origin from one common ancestor through the same processes of speciation resulted in twin-species formation. Direct origin of one species from another seems quite doubtful. Geographical analysis proved most part of T. altaicus area to be situated within the area of $T$. asiaticus and the area of $T$. sajanensis - within the one of T. kytmanovii, correspondingly [2]. We can thus conclude that $T$. altaicus and T. sajanensis originate from T. asiaticus (through $T$. kytmanovii for $T$. sajanensis). In both alpine endemics, there remained tight introgressive exchange with maternal forms, that being proved by molecular analysis [3]. For natural hybrid populations of $T$. altaicus $\times T$. asiaticus (where some plants exhibit intermediate characters or a combination of characters of different species), there was established high rate of pollen fertility [4].

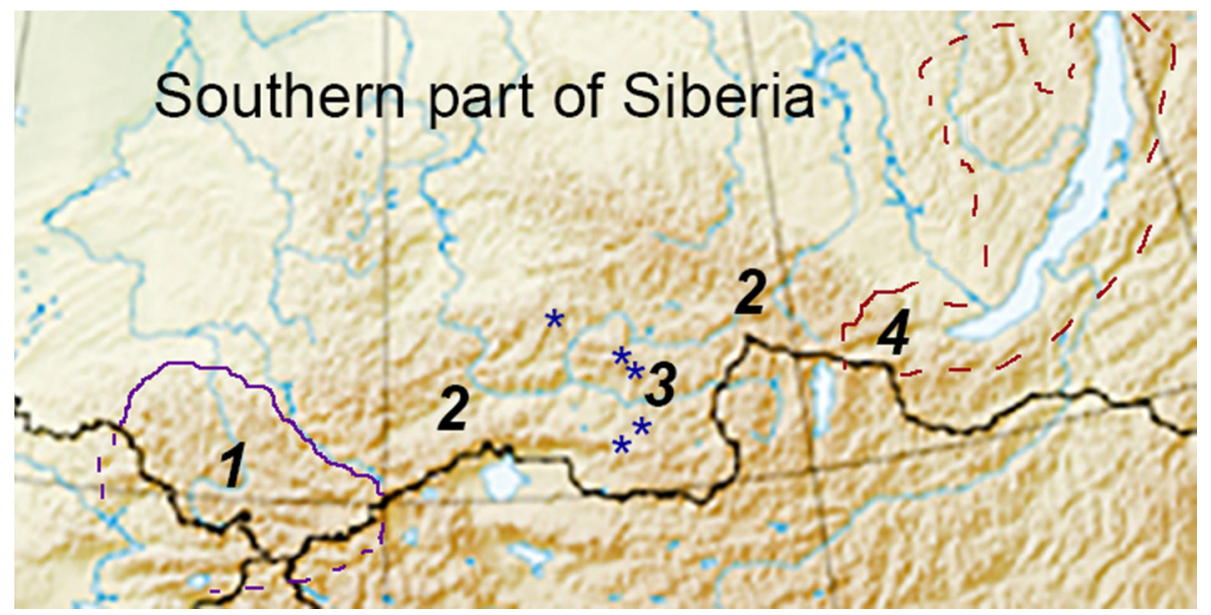

Fig. 1. Territories with different results of disruptive selection in high-mountains of South Siberia. 1 . The area of $T$. altaicus C.A. Meyer; dotted line marks the border that requires verification as there are too few samples in herbaria. 2. Territories with high-mountains occupied by T. asiaticus L. 3 . Territories with single occurrences of samples notably different with T. asiaticus (locations marked with asterisks). 4. Area of T. sajanensis (Malysh.) Sipl. 
In addition, in high-mountains and midlands, there occur single plants which cannot be referred to T. asiaticus, as opposite to the main diagnostic character of this species (petal to sepal length ratio), their petals are considerably shorter. Such forms were found in the most eastern part of the Western Sayan and in the upper Naryn River (the Sangilen Highlands). Locations of point prevalence of such forms are presented in the Fig. 1 (Fig. 1, 3). The forms were identified as T. vitalii N.V. Stepanov, T. sajanensis, and T. sibiricus Schipcz. $[5,6]$. All the descriptions are debatable [7], however, the very fact is beyond doubt that there is some indefinite area of plants with petals notably shorter than the ones of $T$. asiaticus in the high-mountains of Eastern Tyva and the south of Krasnoyarsk Krai. Our expeditions revealed populations with significantly varying ratios of petal length and stamen length among alpine populations of the Ergaki and Akademic Obruchev Ranges (the south of Krasnoyarsk Krai and Eastern Tyva) [1]. These findings do not diminish the importance of the "petal length" diagnostic character for species of the genus Trollius. The region (Fig. 1,3) with occurrence of such variable plants is really unique.

Accordingly, geographical analysis proved the growth of T. altaicus and T. sajanensis species along with alpine forms of $T$. asiaticus within the area of $T$. asiaticus. Such a distribution of species and forms is typical for adjacent sympatry. T. asiaticus with its long wide petals, short styles and beaks should be considered as the ancestor form. That is evident in morphological unsteadiness exhibited by populations with high rate of polymorphism by size and form of flowers and leaf blades, number of petals and sepals, and smooth shift from sepals to petals.

The peculiarity of the adjacent-sympatric speciation is low geographical and hence reproductive isolation. On the other hand, disruptive selection takes place if growing conditions change by climatic or ecological factors [8]. In species and clearly deviating forms, low reproductive isolation causes two opposite processes, as natural selection reinforces divergence but also leads to introgression, which is the exchange of genetic information alongside with permanent spontaneous hybridisation, thus eliminating distinctions. That is why for new species formation by adjacent sympatry, a complex of conditions is required when divergence due to selection considerably exceeds the results of introgression processes. T. asiaticus expresses high plasticity and can grow in highmountains up to $2500 \mathrm{~m}$ above sea level; so the biotic complex intensifying or suppressing seed production of these entomophilous species should be considered as the main factor to cause disruptive selection. We suppose such factors to include not only species composition and behaviour patterns of pollinators, their change according to high-altitude zone being proved by literature [9], but also the insects consuming nectar without pollination and damaging plant reproductive organs.

Analysis of growing conditions under the study showed that $T$. altaicus and $T$. sajanensis speciation takes place at more humid or more high-altitude territories than the high-mountains occupied by $T$. asiaticus.

Tyva has a severe continental climate and there are fairly few suitable places for $T$. asiaticus. The species does not grow in dense massifs, but forms small populations at forest meadows, northern slopes and light coniferous forests around lakes and along rivers. Such a distribution in little groups prevents co-evolution: biotic factors/T. asiaticus.

In more humid and high-altitude regions of the Altai Mountains and Tunka Range, Trollius representatives grow in massive populations crossing several altitude belts. There also appear alpine micro-forms which somewhere enable more or less smooth shift from lowland maternal forms to alpine daughter ones. Most of all, disruptive selection separating daughter forms from lower growing T. asiaticus is expressed above the forest border. We suppose the development of the endemic alpine species $T$. altaicus and $T$. sajanensis to result from this selection. The forms growing within the altitude range between the parental and daughter species are in state of permanent introgression with them. The pair $T$. 
asiaticus $-T$. altaicus has two such forms. They are T. asiaticus with varying petal width and long beaks up to $5 \mathrm{~mm}$ and T. altaicus with short beaks and petals longer than stamens [1]. Both forms are represented well in herbaria of Komarov Botanical Institute RAS, Tomsk University and Central Botanical Garden SB RAS. As for the intermediate forms for the pair T. asiaticua (T. kytmanovii) - T. sajanensis, we believe that one of them also has introgressive origin; its petals are longer than stamens but notably shorter than sepals, beaks 2-4 mm long. This form grows in low-mountains and midlands of the Tunka Range and in the inter-mountain depressions. The other morphologically close and quite steady form grows in large amounts at the Hamar-Daban Ranges and along the shores of Baikal including the Baikal Range (Fig. 1, 4). Introgressive forms act as reproductive barriers, provided the territory for their spread is large enough. However, if such introgressive populations do not form expressed massifs, speciation does not occur. Within such regions (Fig. 1, 3), high-mountains turn to be a zone of devouring of deviating individual plants, even when they are kept by disruptive selection. There, T. asiaticus is wide-spread all over the forest belt, while the upper border of the forest and alpine meadows are occupied by populations in which hybridisation by disruptive forms arising inside these very populations does not result in occurrence of forms with steady morphological characters. That is why in the high-mountains of Eastern Tyva, there grow plants with varying diagnostic characters within one population. If we assume that speciation processes are of the same type in both eastern and western parts of South Siberia mountains, that means populations with varying diagnostic characters are likely to be found in south-eastern parts of the Altai Mountains and north-western part of the Western Sayan as well (probably, at the Salair Ridge, Kuznetskiy Alatau, the Abakan Range, and the northern part of the Shapshal Range).

Thus for efficient adjacent-sympatric speciation in the Trollius genus representatives of South Siberia, two conditions are required:

1. The pair of maternal-daughter species must consist of large enough massifs of populations growing in different belts. That contributes to the introgressive interlayer formation which helps keeping reproductive isolation.

2. There must be biotic factors causing disruptive selection when changing altitude belts and consequently, growing conditions. These factors need further thorough study.

High-mountains, where the mentioned above conditions are not fulfilled, are occupied by $T$. asiaticus or forms being devoured, which is detected by significant intra-population varying of diagnostic characters.

The study was conducted according to the project VI.52.1.3 "Revealing the ways of adaptation in plants to contrast habitation conditions at population and organism levels" № AAAA-A17117012610053-9. Authors are grateful to Ph.D. (Biology) I.V. Han for valuable advice and recommendations.

\section{References}

1. L.V. Buglova, O.S. Zhirova, Bot. Zhurn., 104, 107-123 (2019)

2. N.V. Friesen, Flora of Siberia, 6, 103-108 (1993)

3. L.V. Buglova, N.S. Nuzhdina, Plant Life of Asian Russia, 2, 66-75 (2018)

4. L.V. Buglova, A.S.Gusar, O.V. Dziuba, A.O. Morozova, Trollius L. pollen fertility in situ and ex situ, in: Problems of Botany of South Siberia and Mongolia: collected scientific articles on the materials of the XVIII international scientific-practical conference, 20-23 May 2019, Barnaul, Russia (2019) 
5. N.V. Stepanov, Florogenetic analysis (on the pattern of north-east part of Western Sayan (Krasnoyarsk State University, Krasnoyarsk, Russia, 1994)

6. D.N. Shaulo, A.D. Doduk, N.I. Molokova, Turczaninowia, 6, 35-42 (2003)

7. L.I. Malyshev, Family Ranunculaceae - Lyutikovye, in: Synopsis of flora of Siberia (Izdatelstvo RAN, Novosibirsk, Russia, 2012)

8. V. Grant, Evolution of organisms (Mir, Moscow, 1991)

9. Z.-G. Zhao, Y.-K. Wang, PLOS ONE 10, e0118299 (2015) 